\title{
O gradiente de permissividade e restrição à ocupação (GPRO) como alternativa para o distrito do Riacho Grande, em São Bernardo do Campo - SP
}

\author{
Maira Begalli ${ }^{1}$ \\ Simone Rodrigues de Freitas ${ }^{2}$ \\ Leonardo Freire de Mello ${ }^{3}$
}

\begin{abstract}
Resumo
Riacho Grande é distrito do município de São Bernardo do Campo (SBC) e encontra-se localizado na Região do Grande ABC, no setor sudeste da Região Metropolitana de São Paulo (RMSP). Possui doze bairros, sendo dez rurais e dois urbanos, totalmente inseridos na Área de Proteção de Manancial da Billings, fato que contribui significativamente para a manutenção dos ciclos biológicos e para a prestação de serviços ambientais no estado de São Paulo. O Gradiente de Permissividade e Restrição à Ocupação (GPRO) sugere escalas de uso e ocupação ao zoneamento proposto, considerando as demandas da população local à preservação do manancial, determinando diretrizes para recuperação de APP's, além dos tamanhos e tipos de edificações.
\end{abstract}

Palavras-chave: Riacho Grande. Mata Atlântica. GPRO. Sustentabilidade. Zoneamento.

\begin{abstract}
Riacho Grande is a Sao Bernardo do Campo's (SBC) district and is located in the great ABC region, on the southeast of the Metropolitan Region of Sao Paulo. It has 12 neighborhoods, 10 of them are rural and the other 2 are urban. Once this district is totally inserted in Billings's watershed area it contributes significantly on the maintenance of the biological cycles and so for the environmental services in the state of São Paulo. The Permissivity and Restriction to Occupations Gradient (GPRO) suggests scales of use and occupation to the zoning proposed considering the demands for its population and so for the watershed preservation, determining guidelines for permanent preservation areas recover, and also the types and sizes of edifications on that area.
\end{abstract}

Keywords: Riacho Grande. Brazilian Atlantic Forest. GPRO. Sustainability. Zoning.

\section{Introdução}

Riacho Grande é distrito do município de São Bernardo do Campo (SBC) e encontra-se localizado na Região do Grande $A B C^{4}$, no setor sudeste da Região Metropolitana de São Paulo (RMSP). Possui doze bairros, sendo dez rurais e dois urbanos, e uma população de 29.302 habitantes (IBGE, 2010). O seu bairro central, Rio Grande, localiza-se a 10 quilômetros do centro de SBC. A principal via de acesso ao distrito é a rodovia Anchieta, na altura do quilômetro 29, próximo à interligação da Rodovia Caminho do Mar (Figura 1).

\footnotetext{
1 Doutoranda em Planejamento e Gestão do Território pela Universidade Federal do ABC (UFABC). maira.begalli@ufabc.edu.br

2 Doutora em Geografia. Docente no Programa de Pós-graduação de Planejamento e Gestão do Território na UFABC.simone.freitas@ufabc.edu.br

${ }^{3}$ Doutor em Demografia. Docente no Programa de Pós-graduação de Planejamento e Gestão do Território na UFABC. leonardo.mello@ufabc.edu.br

4 Região do estado de São Paulo, que integra parte da RMSP. A sigla vem das cidades: Santo André (A), São Bernardo do Campo (B) e São Caetano do Sul (C).
} 
Figura 1 - Mapa de Localização do Riacho Grande

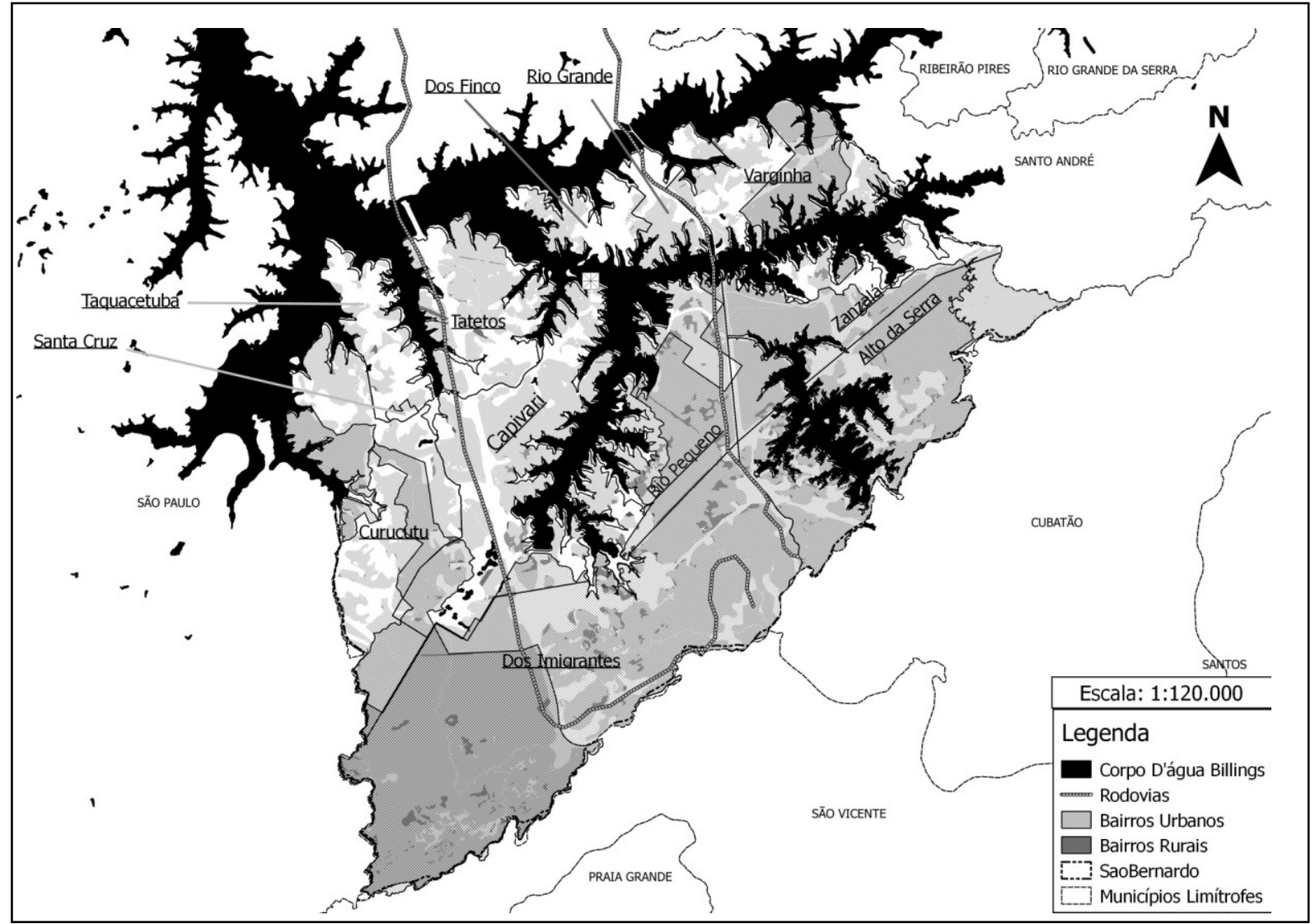

Fonte: Elaborado pelos autores (2015).

O território do distrito agrega mais da metade $(54,7 \%)$ da extensão territorial de SBC, com 223,58 km² (PMSBC, 2015), estando, em sua totalidade, na Área de Proteção de Manancial da Billings (APM-B), fato que contribui significativamente para a manutenção dos ciclos biológicos e para a prestação de serviços ambientais no estado de São Paulo. Porém o distrito cristaliza conflitos que envolvem o manejo dos recursos naturais e o estabelecimento de populações humanas, apresentando cenários complexos acerca da falta de planejamento adequado às demandas e às especificidades do distrito.

O presente trabalho tem como objetivos caracterizar a biodiversidade existente no Riacho Grande, e, assim, delinear um Gradiente de Permissividade e Restrição à Ocupação (GPRO) para o território, considerando o uso sustentável de seu ecossistema e delimitando áreas destinadas à redução da vulnerabilidade socioecológica, à recuperação ambiental e ao controle e à qualificação urbana e ambiental. A seguir apresenta-se a metodologia utilizada e, em seguida, são apresentados os resultados e discussão do estudo. 


\section{Metodologia}

A metodologia utilizada baseou-se na estrutura de Ostrom (2009) para sistemas complexos, que sugere a interação entre o sistema natural (recursos, ecossistema e ambiente biofísico), das populações humanas (ambiente social, econômico e cultural) e das formas de manejo (planos e políticas públicas voltadas ao uso dos recursos ecossistêmicos e ao ordenamento territorial) existentes em um determinado recorte territorial. Para isso, foram coletados dados por meio 1 ) de revisão bibliográfica em publicações temáticas; 2) de pesquisa em bases de dados do município de São Bernardo do Campo, do Estado de São Paulo e do Governo Federal; 3) da observação direta, entre os meses de junho de 2013 e setembro de 2015, realizando visitas de campo e entrevistas livres, não estruturadas, com a população local e com gestores públicos de diferentes secretarias do município de SBC. Para a elaboração dos mapas, foram utilizados o Datum Sirgas 2000, a projeção Universal Transversa de Mercator Fuso 23S, o software livre Qgis5. Ao final, foram gerados produtos na escala 1:120.000.

\section{Resultados e discussão}

Riacho Grande abriga áreas legalmente asseguradas pela Política Nacional das Áreas Protegidas (PNAP), que tem a função de proteger e conservar a biodiversidade e garantir o uso sustentável de seus recursos naturais (VELASQUEZ, 2007), sendo elas duas Unidades de Conservação (UC's), uma Terra Índigena ( $\mathrm{TI}$ ), uma colônia de pescadores artesanais e Áreas de Preservação Permanentes (APP's ${ }^{6}$ ), distribuídas ao longo de seu território (Figura 2, inserida na próxima página).

O distrito está localizado no bioma Mata Atlântica, e, de acordo com a classificação de Köppen para o Estado de São Paulo, seu clima é classificado como subtropical (Cfb), com chuvas distribuídas ao longo do ano e verões amenos (ALVARES et al., 2014).

5 Qgis é um software de informação geográfica, livre e aberto. http://www.qgis.org/.

6 APP'S são áreas protegidas, cobertas ou não de vegetação nativa, com a função ambiental de preservar os recursos hídricos, o fluxo gênico de fauna e flora, o solo, e assegurar o bem-estar das populações humanas (LIMA, 2007). 
Figura 2 - Biodiversidade no Riacho Grande

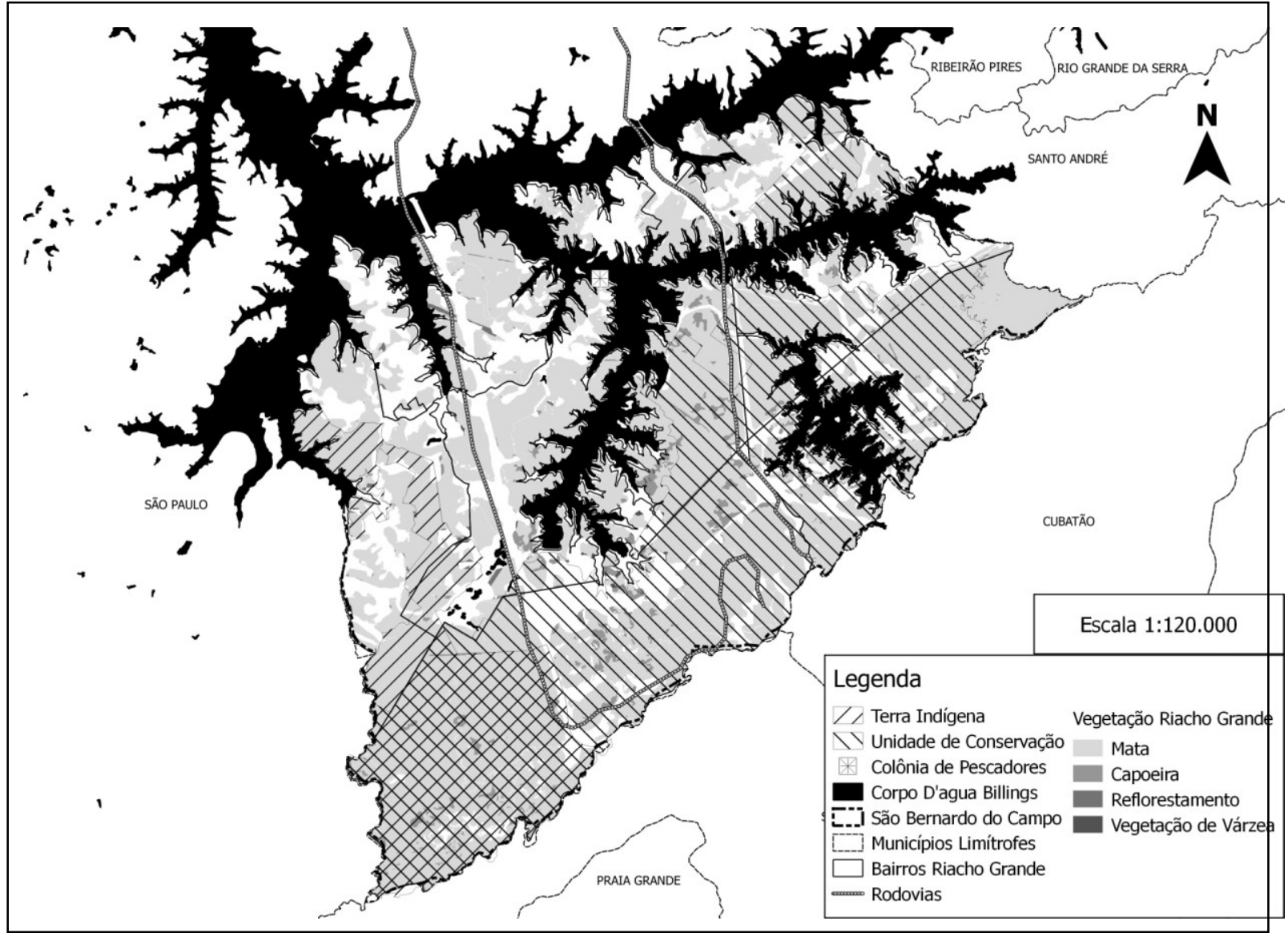

Fonte: Elaborado pelos autores (2015).

\subsection{Biodiversidade do Riacho Grande}

A Mata Atlântica é considerada um hotspot, ou seja, uma das 34 áreas eleitas prioritárias para a conservação da biodiversidade em todo mundo (MYERS et al., 2000). O bioma possui cerca de 2.300 espécies de vertebrados, e 20.000 espécies de plantas vasculares, sendo que aproximadamente 740 espécies dos vertebrados e 8.000 espécies de plantas são endêmicas do bioma (MYERS et al., 2000). Segundo dados da Fundação SOS Mata Atlântica e do Instituto Nacional de Pesquisas Espaciais - INPE (2009), o bioma, atualmente, possui apenas 102.012 quilômetros quadrados $(7,91 \%)$ de sua formação original preservados. Foi declarada como patrimônio brasileiro pela Constituição Federal de 1988, em seu capítulo VI, artigo 225, §4은 (BRASIL, 1988), como Reserva da Biosfera da Organização das Nações Unidas para a Educação, Ciência e Cultura - UNESCO, em 1992 (UNESCO, 2015), e assegurada pela Lei $n^{\circ}$ 11.428/2006, que dispõe sobre a utilização e proteção da vegetação nativa e dá outras providências (BRASIL, 2006).

Riacho Grande contém proporções do seu território no Parque Estadual Serra do Mar, no Núcleo Itutinga, uma UC de proteção integral sob a gestão do Governo do Estado de São Paulo, 
por meio da Fundação Florestal. O Parque Estadual Serra do Mar é a maior área contínua da Mata Atlântica existente no país, com mais de 315.390 hectares de extensão e oito núcleos administrativos: Itutinga-Pilões, Caraguatatuba, Curucutu, Cunha-Indaiá, Picinguaba, Santa Virgínia e Pedro de Toledo, Itariru (SÃO PAULO, 1977).

O Núcleo Itutinga Pilões foi criado no ano de 1977 pelo Decreto Estadual n 10.251, e é composto por proporções territoriais dos municípios de São Bernardo do Campo, Cubatão, São Vicente, Bertioga, Santos, Praia Grande, Santo André, Mogi das Cruzes, Biritiba Mirim e São Paulo, em uma área total de 115.000 hectares. O seu Plano de Manejo foi aprovado pelo Conselho Estadual do Meio Ambiente (CONSEMA), por meio da resolução no 34, em 19 de setembro de 2006 (SÃO PAULO, 1977; 2006; 2008).

Riacho Grande abriga a porção relativa ao Núcleo Administrativo Caminho do Mar, do Núcleo Itutinga Pilões, em uma área de 12.496 hectares. O núcleo administrativo foi estabelecido por meio da Portaria 167, de 01/10/2015, da Fundação Florestal, que é responsável pela gestão de atividades ecoturísticas, como trilhas interpretativas e atividades de educação ambiental, sendo que a visitação ocorre por meio de agendamento prévio (SÃO PAULO, 2015). Além da biodiversidade, possui patrimônios culturais e históricos importantes: a Calçada do Lorena, a Estrada Caminhos do Mar e oito monumentos históricos, construídos em 1922, para a comemoração ao Centenário da Independência do Brasil - a Casa de Visitas do Alto da Serra, o Pouso de Paranapiacaba, Ruínas de Pouso, Belvedere Circular, Rancho da Maioridade, Padrão do Lorena, Pontilhão da Raiz da Serra e o Cruzeiro Quinhentista (SÃO PAULO, 2008).

O distrito possui uma UC municipal, o Parque Natural Estoril Virgílio Simionato. O parque foi instituído como UC pelo decreto municipal 18.684, em 13 de novembro de 2013, com o objetivo de proteger a paisagem natural e possibilitar o desenvolvimento de atividades de educação ambiental, de recreação e turismo ecológico. As instalações do Estoril somam mais de 372 mil metros quadrados, sendo 90\% de cobertura vegetal (PMSBC, 2013).

As formações vegetais encontradas no distrito são Floresta Ombrófila Densa, em fases secundárias, de inicial à média; Floresta Ombrófila Mista (Mata de Araucária); Floresta Estacional Semidecídua e Arbóreo/Arbustiva/Herbácea (MANTOVANI, 2015). A cobertura vegetal existente no Riacho está categorizada em

- Mata: em áreas com fisionomia mais preservada, floresta densa, verde e diversificada, com árvores que atingem até 20 metros de altura;

- Capoeiras: vegetação secundária com algum tipo de degradação, menor e menos diversificada que a floresta original;

- Reflorestamento: florestas com espécies exóticas, como pinheiros e eucaliptos;

- Várzea: ocorre ao longo dos cursos d'água (INSTITUTO FLORESTAL, 2016).

Embora não existam inventários detalhados de fauna e flora específicos do distrito, a população local relata a ocorrência de importantes espécies, principalmente nos bairros da zona 
rural, como pau-brasil, bromélia, tamanduá-mirim e bugio.

O distrito abriga uma biodiversidade cultural constituída por populações indígenas e de pescadores. Entretanto, o processo de crescimento desordenado fez com que esses indivíduos enfrentassem uma série de desafios envolvendo a obtenção de recursos e o manejo de seus territórios. O direito dessas populações está assegurado pela Política Nacional de Povos e Comunidades Tradicionais (PNPCT), que garante aos povos e comunidades tradicionais o acesso aos serviços de saúde, a processos educativos formais e não-formais, à infraestrutura adequada às suas realidades socioculturais, e o acesso aos recursos naturais que tradicionalmente utilizam para sua reprodução física, cultural e econômica. Os instrumentos de implementação dessa política são a Política Nacional de Desenvolvimento Sustentável dos Povos e Comunidades Tradicionais, os Planos de Desenvolvimento Sustentável dos Povos e Comunidades Tradicionais, fóruns regionais e locais, e o Plano Plurianual - PPA (BRASIL, 2007). Porém, no Riacho Grande, a PNPCT ainda não foi implementada.

A TI Tenodé Porã (Figura 3), da etnia Guarani Mbyá, localiza-se ao longo dos bairros Curucutu e Imigrantes, em uma área de 15.969 hectares. Possui uma aldeia, a Brilho do Sol (Tekoa Kuaray Rexakã, em guarani), com acesso lacustre por meio da Estrada da Água Limpa. A TI foi delimitada em 18 de abril de 2012 pela Fundação Nacional do Índio, para assegurar o direito às áreas que os Mbyá tradicionalmente ocuparam, próximas à Serra do Mar (FUNAl, 2012).

Figura 3 - Índios da Aldeia Tekoa Kuaray Rexakã

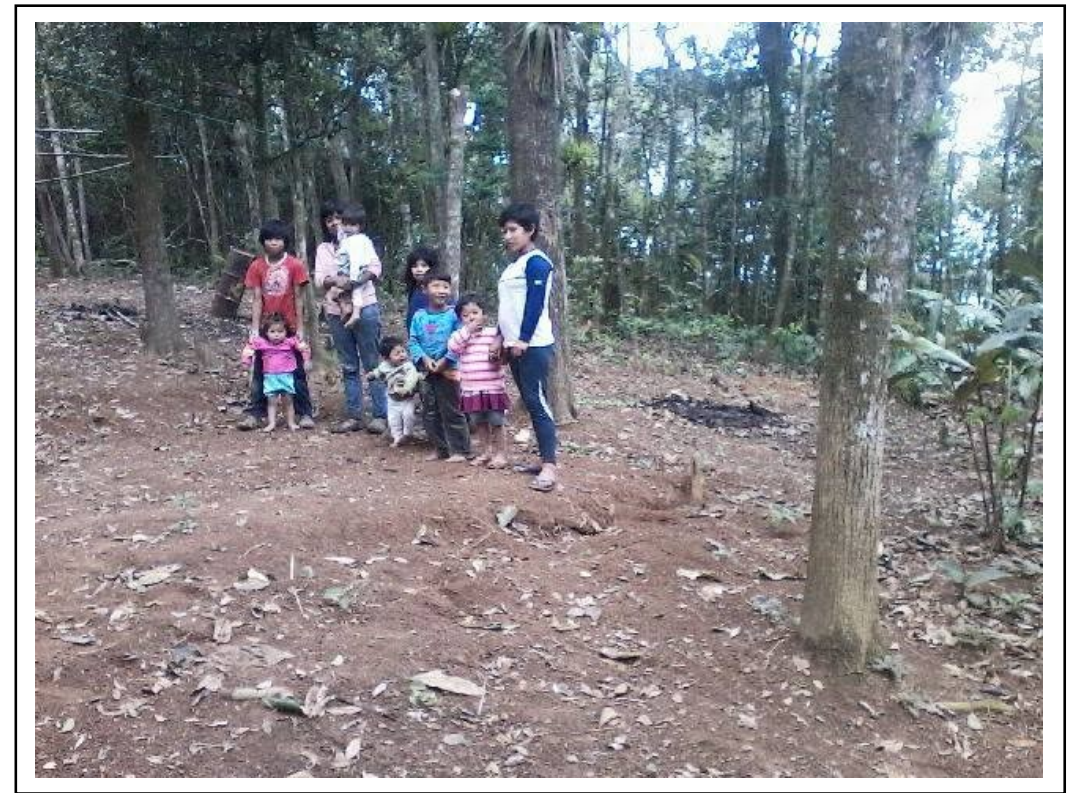

Fonte: Kuaray Popygua em 10/outubro/2015.

Os Mbyá que se estabeleceram no Riacho Grande antes habitavam a aldeia do Krukutu, localizada no distrito de Parelheiros (BRASIL, 1987). Contudo, por conta da limitação territorial e 
de recursos, passaram a encontrar dificuldades para realizar as atividades de subsistência. Assim, decidiram migrar para outro território e estabelecer uma nova aldeia. Na época, o proprietário da área entrou com uma ação para reintegração de posse, que foi indeferida pela justiça, pois, segundo o mapeamento da FUNAI, a área era de ocupação tradicional dos Guaranis (BRASIL, 1988; 1996).

Com a supressão da cobertura vegetal e a perda da biodiversidade do bioma Mata Atlântica, aumenta também a indisponibilidade de áreas e recursos naturais para essa população. Desse modo, a busca por novos territórios pode se tornar cada vez mais frequente para os Mbyá. Por outro lado, a maior pressão advinda da caça, da pesca e do desflorestamento para o estabelecimento de hortas e roças, ainda que em pequena escala, tende a aumentar a pressão do bioma, já fragilizado devido a outras atividades impactantes (OLMOS; TEINER; GALETTI, 2004).

A colônia de pescadores artesanais "José Bonifácio" encontra-se no bairro do Tatetos, na Rua Rio Acima, no 5.930, próximo à travessia da balsa João Basso (Figura 4). A capataz é Vanderléa Rochumback, pescadora, natural do Riacho Grande. Vanderléa é um nome bastante respeitado entre os pescadores. Ela representa o ativismo pela igualdade de gênero em um ambiente predominantemente masculino, onde as mulheres apenas "cuidavam da limpeza do pescado".

\section{Figura 4 - Colônia de pescadores José Bonifácio}

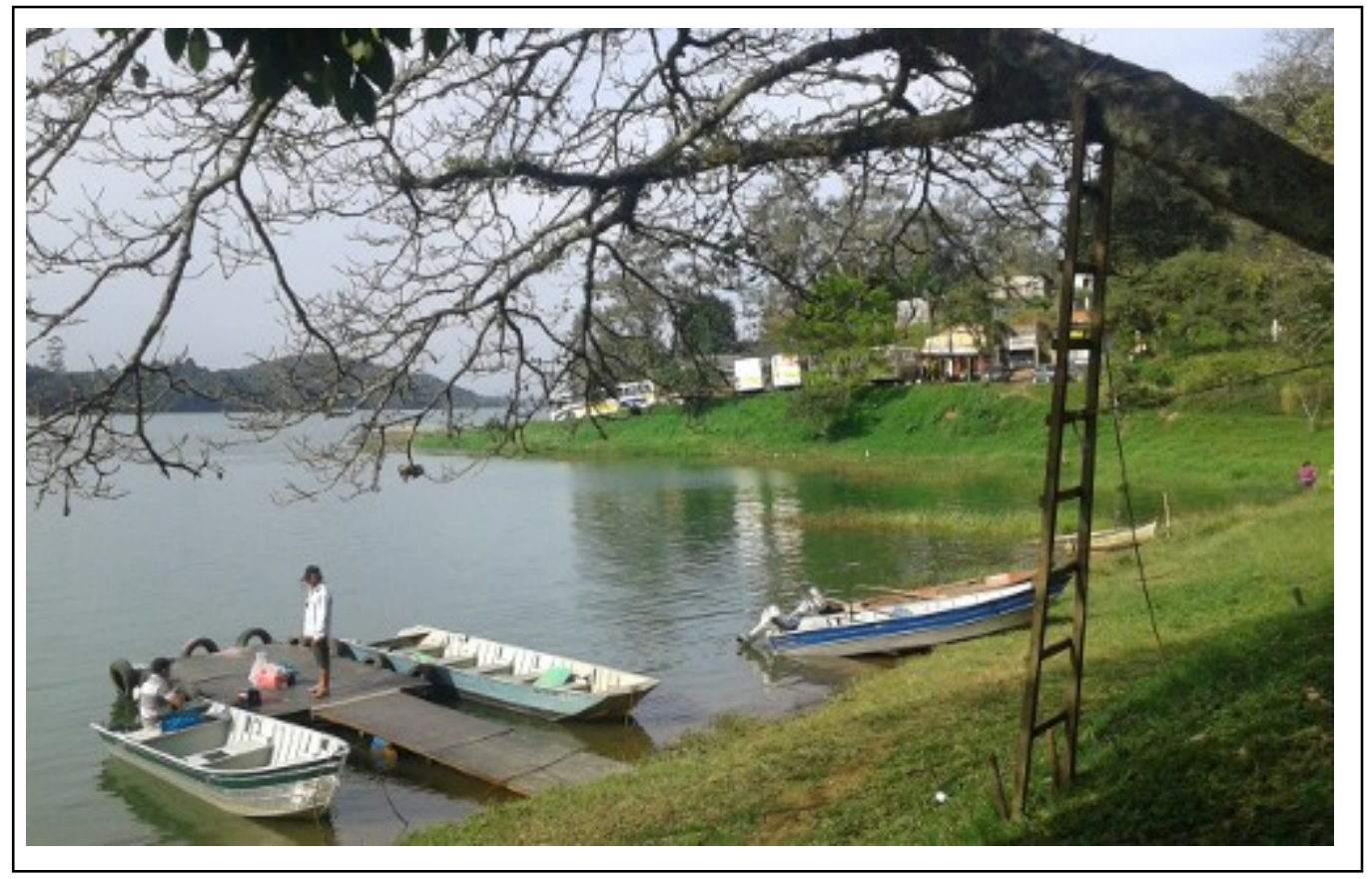

Fonte: Maira Begalli em 6/julho/2015.

Oficialmente estabelecida em 2008, a colônia possui como objetivo orientar os 
pescadores e as pescadoras do Riacho Grande na busca de seus direitos sobre a atividade da pesca, regulamentada pela Lei no 11.699/2008 (BRASIL, 2008). A sede administrativa da colônia possui escritório com telefone fixo, computadores com acesso à internet, energia elétrica e fossa séptica. Contabiliza cerca de 500 cadastros, entre pescadores e pescadoras artesanais profissionais, que utilizam, em suas atividades, a técnica de rede de espera, canoas a remo ou com motor.

A sede também é o local de residência de 21 pessoas da família Rochumback, residente do Riacho Grande desde o final da década de 1940, quando o Serviço de Piscicultura da Ligth iniciou a introdução de carpas (Cyprinus carpio) e tilápias (Tilapia rendalli) na Billings (ROCHA; PEREIRA; PÁDUA, 1985). O patriarca da família Rochumback, neto de imigrantes alemães, morava em um barco, antes de se estabelecer onde hoje funciona a sede da colônia. A família não possui escritura, e a área, ocupada em 1949, trata-se de uma propriedade particular.

Segundo os pescadores da colônia, no ano de 2013, um laudo da Companhia Ambiental do Estado de São Paulo (CETESB) indicou a presença de metais pesados (cobre, cromo, mercúrio e zinco) nos sedimentos da represa e nas vísceras dos peixes pescados no entorno da colônia. Os pescadores afirmam que os metais encontrados não são nocivos, pois "todo mundo compra, e ninguém passa mal" e "os pescadores mais velhos sempre comeram o peixe da represa e nunca tiveram nenhuma doença". O peixe é a base da dieta da maioria dos pescadores do distrito, também composta por vegetais, ovos e aves (cultivados em pequenas propriedades do entorno) além de alguns itens industrializados encontrados em vendas e supermercados do entorno.

Metais pesados são essenciais ao funcionamento de organismos vivos, porém são bioacumulativos e biomagnificantes. Assim, em altas concentrações, são altamente nocivos aos ecossistemas e às populações humanas. Resíduos urbanos, efluentes industriais e aterros sanitários constituem fontes importantes de contaminação. Uma vez presentes nos corpos d'água, atingem os peixes, a partir da cadeia alimentar e/ou pelo epitélio das brânquias, concentrando-se nos músculos, no tecido adiposo e nas vísceras, que contaminarão os indivíduos que se alimentarem deles (PORTO; ERTHUR, 2009).

\subsection{Zoneamento Proposto pela Nova Lei da Billings e pelo Plano Diretor de SBC}

Com a regulamentação da Lei no 13.579/2009, conhecida como a "Nova Lei da Billings", o distrito do Riacho Grande foi divido em áreas de intervenção, com diretrizes e normas específicas, com o objetivo de garantir o abastecimento público e a manutenção dos serviços ambientais prestados pelo manancial (SÃO PAULO, 2009). A Lei delimitou cinco compartimentos ambientais e quatro áreas de intervenção, sendo que o recorte territorial do Riacho Grande contempla duas áreas de intervenção (Área de Ocupação Dirigida e Área de Restrição à Ocupação) e quatro compartimentos ambientais (Figura 5): 
- Capivari-Pedra Branca, constituído por áreas de drenagem das sub-bacias dos braços Capivari e Pedra Branca;

- Corpo Central II, constituído pelas áreas de drenagem das sub-bacias contribuintes do Corpo Central do Reservatório na área de expansão urbana de SBC;

- Rio Grande e Rio Pequeno, constituído pelas áreas de drenagem dos braços dos rios Grande e Pequeno, incluindo as sub-bacias de contribuição do Pedroso e Ribeirão da Estiva;

- Taquacetuba-Bororé, constituído pela península do Bororé e pelas áreas de drenagem dos contribuintes do braço do Taquacetuba, nas margens oeste e sul dos municípios de São Paulo e São Bernardo do Campo (SÃO PAULO, 2009).

Figura 5 - Mapa da Nova Lei da Billings aplicada ao Riacho Grande

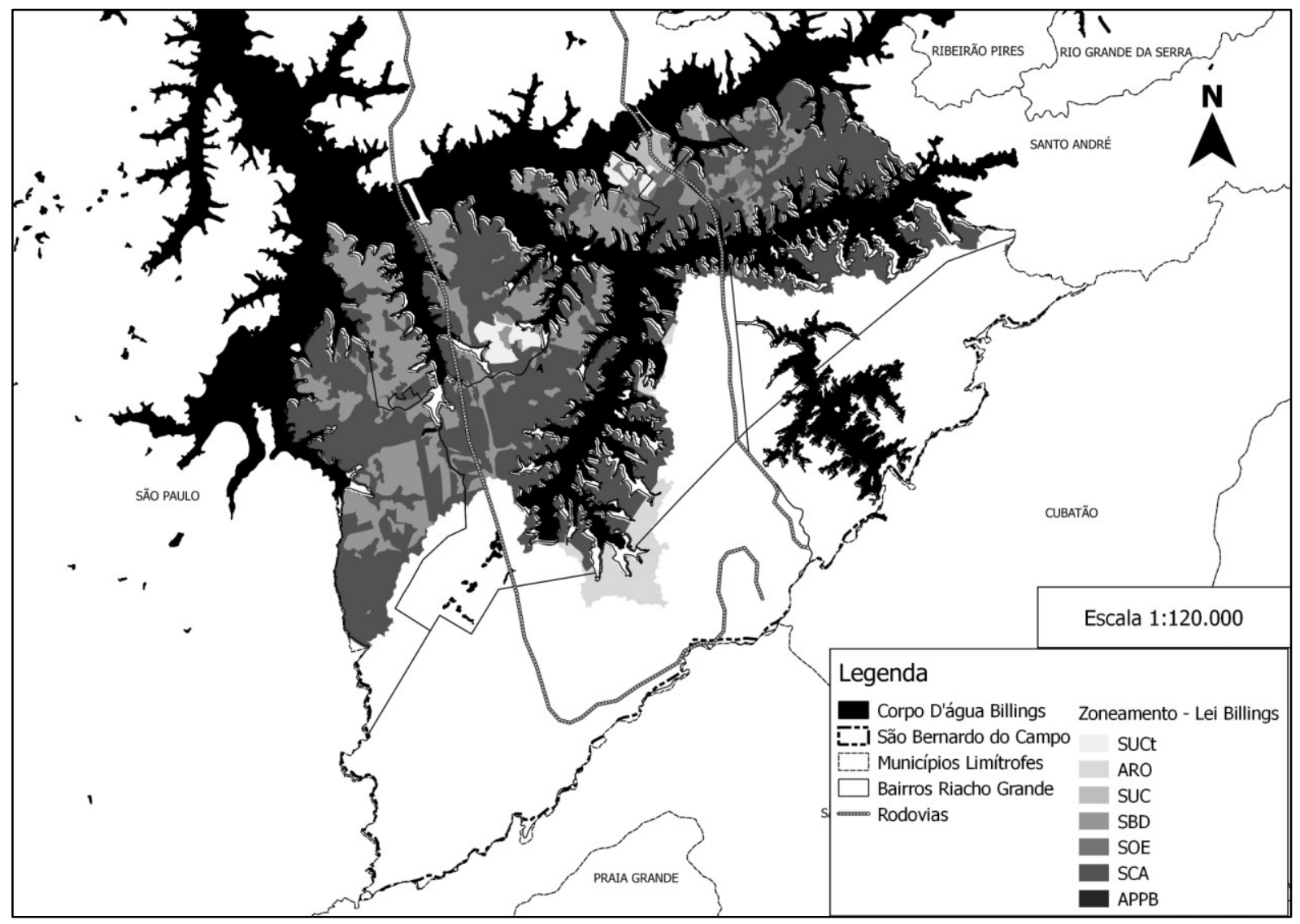

Fonte: Elaborado pelos autores (2015).

No ano de 2001, o Estatuto da Cidade (Lei Federal no 10.257) tornou obrigatória a implementação dos Planos Diretores (PD) aos municípios com mais de 20 mil habitantes, integrantes de áreas de especial interesse turístico ou ambiental, e interessados em realizar o seu parcelamento territorial (BRASIL, 2001). Em cumprimento ao Estatuto da Cidade, a PMSBC realizou uma série de consultas públicas, para delinear o PD Participativo de São Bernardo do 
Campo, instituído pela Lei Municipal no 6.184 (PMSBC, 2011). No mês de janeiro de 2015, a administração municipal concluiu a compatibilização do PD aos critérios estabelecidos pela "Nova Lei da Billings" (Figura 6).

Os bairros Imigrantes, Rio Pequeno, Alto da Serra, assim como a metade da proporção territorial de Zanzalá, foram delimitados dentro da Macrozona de Proteção trechos do Parque Estadual Serra do Mar e foi destinada à "preservação e à recuperação ambiental" e à "provisão de áreas para o desenvolvimento estratégico do município" (PMSBC, 2011).

Figura 6 - Mapa do Plano Diretor de SBC aplicado ao Riacho Grande

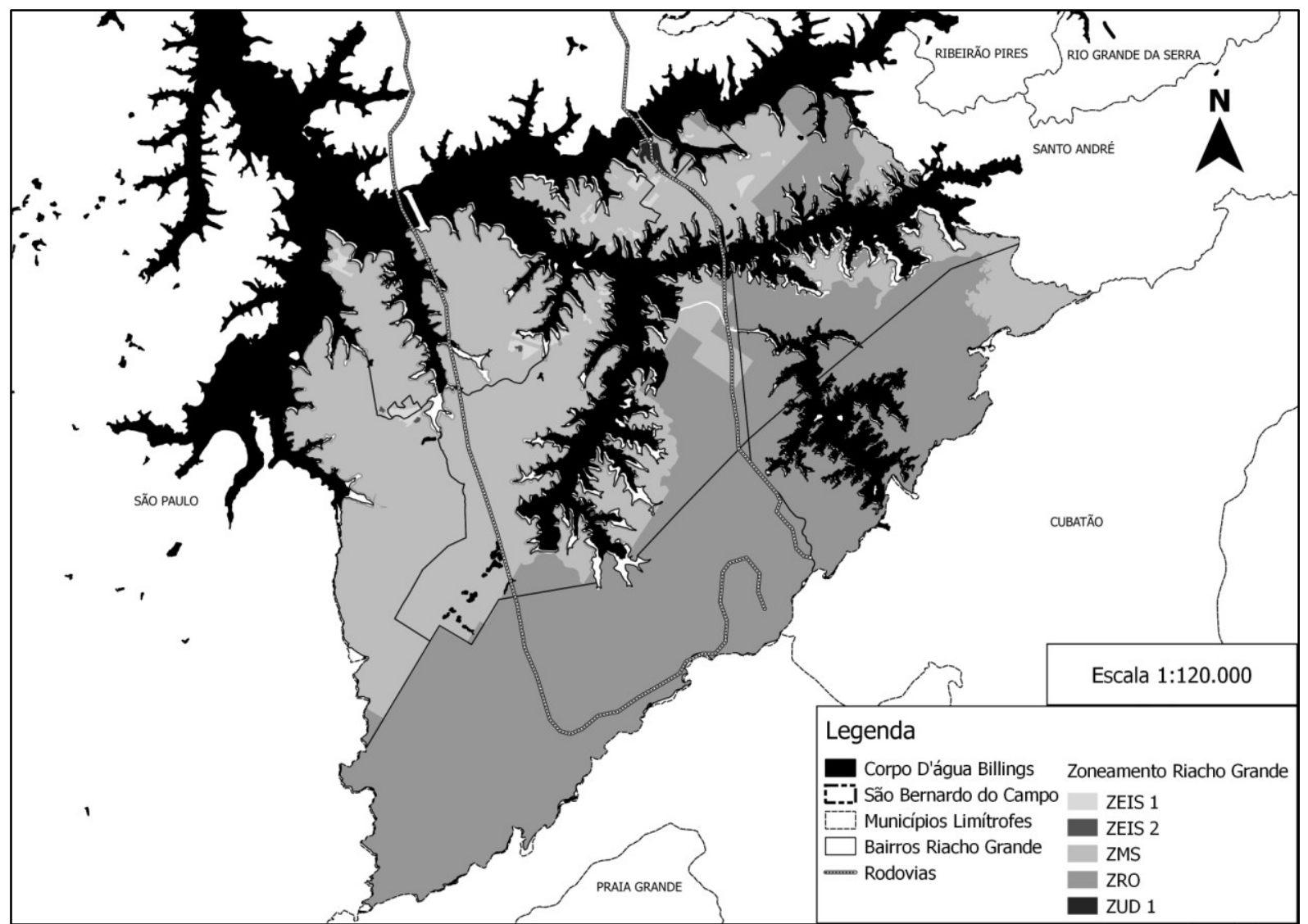

Fonte: Elaborado pelos autores (2015).

Os bairros restantes foram delimitados na Macrozona de Proteção e Recuperação do Manancial (MPRM), voltada à "conservação das características naturais do território", à "recuperação ambiental", à "regularização fundiária sustentável", assim como à implementação de programas de "fomento e apoio ao manejo sustentável" (PMSBC, 2011).

O PD atribuiu proporções destinadas à Zona de Manejo Sustentável (ZMS) em nove bairros do distrito (localizados tanto na zona rural como na zona urbana), à Zona de Uso Diversificado 1 (ZUD1) no Rio Grande, e à Zona de Restrição à Ocupação (ZRO) nos bairros 
Varginha, Imigrantes, Alto da Serra e Rio Pequeno (Tabela 1).

A ZMS compreende áreas em que o uso do território e a realização de atividades estão sujeitas ao licenciamento ambiental. A ZUD1, delimitada no bairro do Rio Grande, destina-se aos usos residenciais e não residenciais distribuídos por nível de incomodidade, sendo que o recorte territorial correspondente à ZUD1 é relativo à orla da Prainha, ao calçadão e ao centro turístico do Riacho (PMSBC, 2011).

Tabela 1 - Macrozoneamento e zoneamento estabelecidos pelo Plano Diretor de São Bernardo do Campo aos bairros do Riacho Grande

\begin{tabular}{lll}
\hline Bairro & Macrozoneamento PD & Zoneamento PD \\
\hline Dos Fincos & MPRM & ZMS, ZEIS 1 \\
Rio Grande & MPRM & ZMS, ZEIS 1, ZUD1 \\
Alto da Serra & MPA & ZMS, ZRO \\
Capivari & MPRM & ZMS \\
Curucutu & MPRM & ZMS \\
Rio Pequeno & MPA & ZMS, ZEIS 1, ZRO \\
Imigrantes & MPA & ZRO \\
Santa Cruz & MPRM & ZEIS 1, ZEIS 2 \\
Taquacetuba & MPRM & ZMS, ZEIS 1 \\
Tatetos & MPRM & ZMS, ZEIS 1, ZEIS 2 \\
Varginha & MPRM & ZMS, ZEIS 1, ZRO \\
Zanzalá & MPA, MPRM & ZMS, ZRO \\
\hline
\end{tabular}

Fonte: PMSBC (2011).

A Zona de Restrição à Ocupação (ZRO), definida como "área especial de interesse ambiental pertencente à APM-B", é encontrada em Zanzalá, Varginha, Imigrantes, Rio Pequeno e Alto da Serra. Em sete bairros do distrito (Fincos, Rio Grande, Rio Pequeno, Santa Cruz, Taquacetuba, Tatetos e Varginha), foram estabelecidas Zonas Especiais de Interesse Social (ZEIS 1 e 2). As ZEIS 1 são destinadas à regularização fundiária, e as ZEIS 2, à edificação de habitação de interesse social ou de mercado popular, em áreas consideradas "não edificadas" ou "subutilizadas". As ZEIS devem atender aos parâmetros da legislação referente ao coeficiente de aproveitamento, à taxa de permeabilidade, ao índice de área vegetada e ao parcelamento do lote mínimo (PMSBC, 2011).

Apesar de enfatizar premissas como "regularização fundiária sustentável" e "fomento e apoio ao manejo sustentável", o Plano Diretor não detalha ou estabelece diretrizes envolvendo 
o tipo de material, técnicas e tecnologias (como edificações baseadas em permacultura, cisternas e composteiras comunitárias, miniestações de tratamento de esgoto, e habitação de interesse social destinadas à produção familiar agroecológica e à prestação de serviços ecossistêmicos, por exemplo), que deveriam ser utilizadas em um território com características muito distintas das existentes na sede do município. Também é contraditória a afirmação de que a MPA seria destinada simultaneamente à "preservação ambiental" e à "provisão de áreas para o desenvolvimento estratégico do município", uma vez que o modelo de desenvolvimento predominante e aplicado arbitrariamente em todo país, desde o período colonial, tem se baseado na exploração e na degradação dos ecossistemas em detrimento da "modernização" e do capital.

Marques (2015) e Klein (2014) afirmam que há uma grande armadilha implícita nos ideais de desenvolvimento contemporâneos, já que, quanto maior a escala de exploração de energia, minerais, solo, água, proteína animal (e outros recursos), mais escassos os recursos se tornam, e, consequentemente, mais poluente e impactante será a sua exploração. Porém, equivocadamente, muitos governos e corporações insistem em afirmar que, com uma pequena diminuição na emissão de gases do efeito estufa e com o estabelecimento de ações para a mitigação de impactos, seria possível compatibilizar as expectativas de desenvolvimento e crescimento econômico contínuo com a manutenção dos ecossistemas.

\subsection{O GPRO aplicado ao Riacho Grande}

O GPRO 7 é uma metodologia que sugere escalas de uso e ocupação ao zoneamento proposto pelos PD's de municípios localizados em áreas que prestam importantes serviços ambientais, por meio de cinco categorias (Tabelas 2 e 3). Para isso, são considerados três gradientes (baixo, médio e alto) de 1. Preservação (Integridade e Contiguidade do Ecossistema); 2. Acessibilidade (Proximidade aos Eixos Estruturantes de Transformação e a Equipamentos e Serviços); e 3. Ocupação (Intensidade de Usos e Atividades).

7 O GPRO foi desenvolvido por Maira Begalli, Luciana Travassos e Silvana Zioni, durante o Ateliê Ensaios Urbanos, na Universidade Federal do ABC (UFABC), entre os meses de outubro e dezembro de 2014. Mais informações em http://gestaourbana.prefeitura.sp.gov.br/atelier-ensaios-urbanos-2. 
Tabela 2 - Parâmetros e Categorias aplicadas ao GPRO

\begin{tabular}{ll}
\hline \multicolumn{1}{c}{ Parâmetros } & \multicolumn{1}{c}{ Categorias } \\
\hline Alto Grau de Ocupação & Requalificação Ambiental (5) \\
Alto Grau de Preservação & Conservação Ambiental (1) \\
Alto Grau de Acessibilidade & Ocupação Socioecológica (4) \\
Médio Grau de Ocupação & Desenvolvimento Agroecológico (3) \\
Médio Grau de Preservação & Recuperação Ecológica (2) \\
Médio Grau de Acessibilidade & Ocupação Socioecológica (4) \\
Baixo Grau de Ocupação & Desenvolvimento Agroecológico (3) \\
Baixo Grau de Preservação & Recuperação Ecológica (2) \\
Baixo de Acessibilidade & Conservação Ambiental (1)
\end{tabular}

Fonte: Begalli, Travassos e Zioni (2014).

Tabela 3 - Detalhamento das Categorias do GPRO

Categoria

1. Conservação Ambiental

2. Recuperação Ecológica

3. Desenvolvimento Agroecológico

\section{Descrição}

A função dessas áreas é a prestação de serviços ambientais. Os parâmetros de uso devem ser definidos nos Planos de Manejo. São admitidos usos e atividades destinados à educação ambiental, à pesquisa e ao ecoturismo.

Áreas desflorestadas que sofreram pressão antrópica, porém que se encontram desocupadas. Destinadas à recuperação ecológica, por meio do plantio de espécies nativas, com o objetivo de recuperar a prestação dos serviços ecossistêmicos. São admitidos usos e atividades destinadas à educação ambiental, à pesquisa e ao ecoturismo.

Assentamentos de baixa densidade de ocupação, compatíveis à manutenção dos serviços ambientais. Destinados a lotes de 1 hectare para produção familiar agroecológica, recuperação florestal e prestação de serviços ambientais, em assentamentos periurbanos localizados em áreas desocupadas, com baixa infraestrutura e próximos às APP's.

(Continua) 


\begin{tabular}{ll}
\hline \multicolumn{1}{c}{ Categoria } & \multicolumn{1}{c}{ Descrição } \\
\hline 4. Ocupação Socioecológica & Áreas próximas às redes de transporte, as quais já \\
& sofrem grande pressão antrópica, mas ainda não \\
& foram ocupadas. Destinadas à manutenção de APP's e \\
& implementação de infraestruturas baseadas em \\
& parâmetros sustentáveis, seguindo padrões \\
& construtivos e aportes tecnológicos (baseados em \\
& permacultura) que garantam a redução de impactos \\
& ambientais e a economia de recursos naturais. \\
& Áreas caracterizadas por densos assentamentos \\
5. Requalificação Ambiental & sempre dispõem de infraestrutura. As intervenções de \\
& urbanificação e melhoria do habitat nessas áreas \\
devem recuperar as APP's, segundo os parâmetros \\
socioecológicos da ocupação.
\end{tabular}

Fonte: Begalli, Travassos e Zioni (2014).

No Riacho Grande, a aplicação do GPRO indica um grande potencial para o desenvolvimento de projetos direcionados à produção familiar orgânica em pequena escala (agricultura, apicultura, fruticultura, avicultura, suinocultura). Estes, seriam baseados em sistemas agroflorestais; à recuperação de APP's e de áreas degradas; ao restabelecimento e à manutenção de ilhas de biodiversidade, assim como do fluxo gênico da fauna e flora (Figura 7 e Tabela 4).

O PD de SBC, a ZRO e a ZMS compreendem a maior proporção territorial do distrito e estão localizadas na zona rural. Possuem baixa ocupação e acessibilidade, e alto nível de preservação. Essas áreas estariam aptas ao desenvolvimento de propostas voltadas à conservação ambiental (Categoria 1) por meio da ampliação das áreas das Unidades de Conservação já existentes no distrito, formando mosaicos de biodiversidade no território, os quais garantiriam o fluxo gênico e a manutenção dos serviços ecossistêmicos. 
Figura 7 - GPRO aplicada ao distrito do Riacho Grande

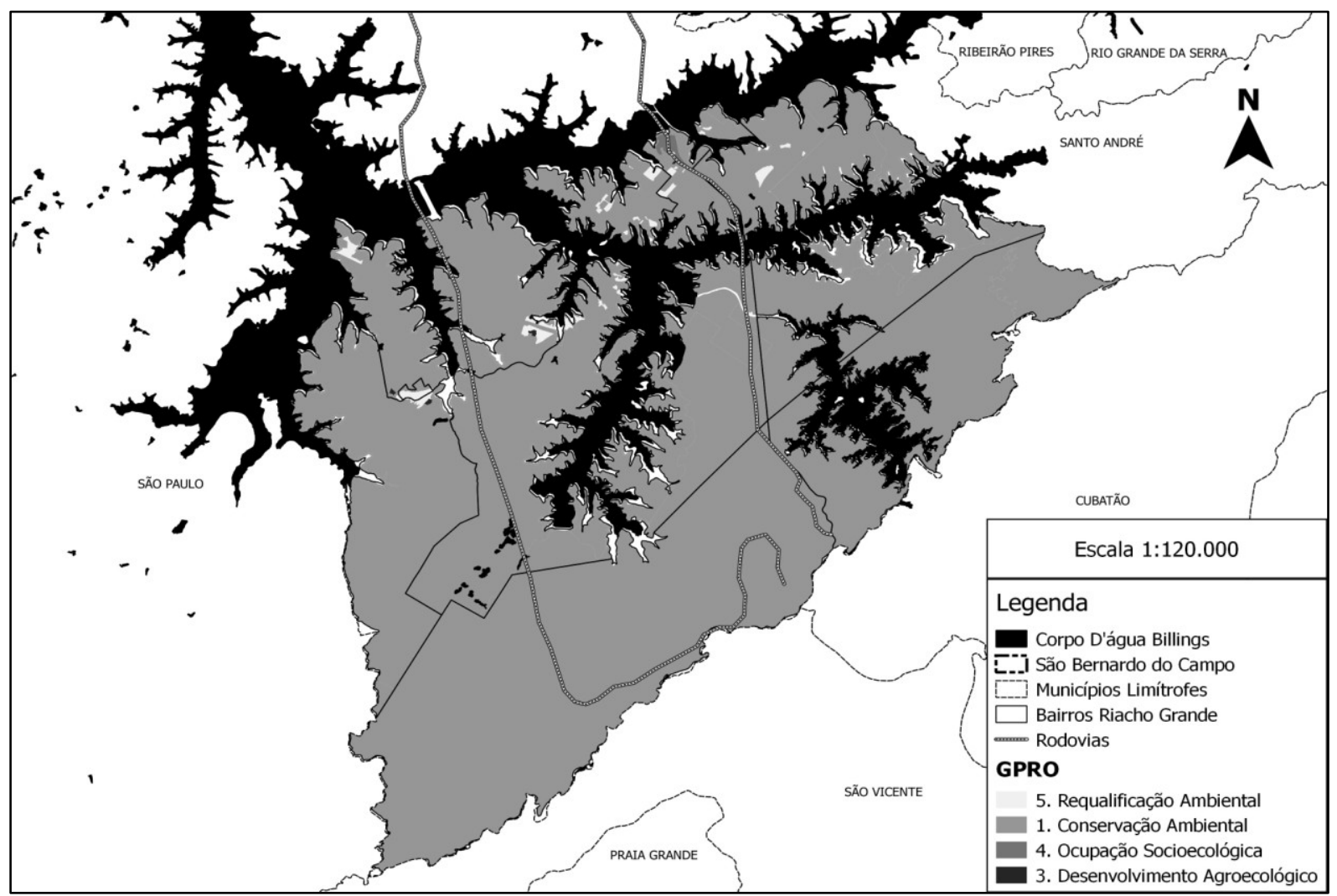

Fonte: Elaborado pelos autores (2015).

Poderia ser realizado o estabelecimento de centros de pesquisas avançadas, voltados à sustentabilidade, a atividades de ecoturismo e a ações envolvendo o Pagamento por Serviços Ambientais (PSA), por meio da zeladoria dos recursos ecossistêmicos, empregando a população local, sem descaracterizar o território e os indivíduos. Contudo, o PD também demarcou proporções dessas áreas contidas nos bairros dos Tatetos e Curucutu (ao lado da TI), próximas à Rodovia dos Imigrantes (a única via de acesso), como Zonas Especiais de Interesse Estratégico ZEIE, explicitando uma dissonância entre as propostas atreladas à sustentabilidade dos ecossistemas existentes no distrito e a exploração dos recursos naturais por parte da administração pública. 
Tabela 4 - GPRO aplicado ao Riacho Grande, de acordo com o PD de SBC

\begin{tabular}{|c|c|c|c|c|}
\hline $\begin{array}{c}\text { Zoneamento do } \\
\text { PD }\end{array}$ & Ocupação & Preservação & Acessibilidade & Categoria \\
\hline ZRO & baixa & Alta & baixa & 1. Conservação Ambiental \\
\hline ZMS & baixa & Alta & baixa & 1. Conservação Ambiental \\
\hline ZUD1 & alta & Baixa & alta & 4.Ocupação Socioecológica \\
\hline ZEIS 1 & alta & Baixa & média e baixa & 5.Requalificação Ambiental \\
\hline ZEIS 2 & baixa & Média & média e baixa & 3.Desenvolvimento agroecológico \\
\hline
\end{tabular}

Fonte: PMSBC (2011).

A ZUD1 delimitada pelo Plano Diretor é relativa à área da Prainha e ao centro turístico do Riacho Grande. Localiza-se na zona urbana, no bairro central Rio Grande, e também foi considerada como Centralidade pelo Plano Diretor. Trata-se de uma área de alta ocupação e acessibilidade. Apesar de estar localizada em APP, existe uma baixa preservação ambiental, provocada pelo alto fluxo de turistas aos finais de semana e pela poluição do manancial. Para essa zona, a ocupação socioecológica (Categoria 4) envolveria, além da adoção de infraestruturas físicas menos impactantes, o delineamento de atividades não predatórias e a reformulação das já desenvolvidas, como, por exemplo, transformar a feirinha de venda de produtos asiáticos e sem identidade, que acontece aos domingos, numa feira de alimentos orgânicos, cultivados por produtores locais.

As ZEIS's 1 foram delimitadas em bairros das zonas rurais e urbanas, sendo que, em algumas dessas áreas, existe média acessibilidade, e, em outras, baixa. São áreas de alta ocupação e baixa preservação ambiental, compostas por assentamentos precários ou loteamentos irregulares. A Prefeitura de São Bernardo do Campo não cogita a realocação desses indivíduos para a sede do município. Nessas áreas, é passível a requalificação ambiental (Categoria 5), e não projetos de urbanização integrada, baseados nos modelos aplicados na sede do município de SBC - uma vez que se encontram em áreas de relevância ambiental, prestadoras de serviços ecossistêmicos para a RMSP e para o estado de São Paulo. Os projetos de requalificação ambiental para cada ZEIS 1 demarcada, obrigatoriamente, deveriam ser integrados a atividades de esclarecimento para a população sobre as especificidades do território e sua importância na realização de serviços ecossistêmicos (que são essenciais para a manutenção da vida na Terra), explicitando os porquês da impossibilidade da implementação das infraestruturas "iguais" às dos munícipes da zona urbana de São Bernardo.

De acordo com o Plano Diretor (PMSBC, 2011), as ZEIS 2 estão destinadas à construção 
de moradia popular. Essas áreas foram delimitadas próximas às ZEIS 1 do Santa Cruz e do Tatetos. Devido à baixa ocupação e acessibilidade, e à média preservação, estariam aptas à categoria 3, "Desenvolvimento Agroecológico", ou seja, à implementação de assentamentos com lotes de 1 hectare, destinados à produção familiar agroecológica, à recuperação florestal e a projetos de PSA. Por estarem localizadas muito próximos à ZEIS 1, as ZEIS 2 poderiam abastecer a população do entorno e também possibilitar novos arranjos produtivos locais sustentáveis.

\section{Considerações finais}

Muitas das características encontradas no Riacho Grande reafirmam e reproduzem os conflitos e as potencialidades presentes em muitos territórios brasileiros localizados em áreas de relevante diversidade biológica. A administração pública de SBC tem implementado, no Riacho Grande, infraestruturas baseadas nos modelos dos bairros urbanos do município, sublinhando um modelo de desenvolvimento relacionado ao consumo de matérias-primas, poluição e descarte em larga escala. Elementos sustentáveis e projetos alternativos para a infraestrutura pública, envolvendo a manutenção e restauração dos serviços ambientais, a bioconstrução, insumos de baixo impacto ambiental, asfalto ecológico, iluminação inteligente, utilização de água de chuvas, coleta seletiva direcionada a resíduos eletrônicos, frotas de veículos elétricos ou a gás não são utilizados.

Ainda que a população local esteja informada sobre a importância do meio ambiente equilibrado, valorize a biodiversidade e a beleza cênica do Riacho Grande, falta-Ihe clareza quanto à importância da recuperação e da preservação dos ecossistemas locais, uma vez que regiões metropolitanas dependem cada vez mais de áreas florestadas para garantir serviços ecossistêmicos como chuvas na quantidade e na distribuição adequada, regulação do clima, recarga do lençol freático, manutenção de espécies polinizadoras e fornecimento de alimentos livres de agrotóxicos. Desse modo, ao optar por um modelo baseado na lógica das grandes cidades, que reafirma desigualdades, replica infraestruturas impactantes, proporciona a exploração e o consumo em larga escala, Riacho Grande terá como consequência a perda dos serviços ecossistêmicos e da possibilidade de conceber propostas mais orgânicas para o turismo, educação, trabalho e renda, habitação e infraestruturas locais.

Reverter esse quadro e iniciar uma trajetória sustentável, voltada à recuperação e à preservação de seu ecossistema e ao empoderamento da população é um grande desafio para a administração pública, as organizações não governamentais, a sociedade civil, ativistas e pesquisadores, que implicará o delineamento de novos arranjos territoriais, e não apenas a continuidade dos já existentes. Nesse sentido, o GPRO pode ser uma ferramenta útil, pois considera não apenas as demandas da população local, mas também a preservação do manancial, determinando diretrizes para recuperação de APP's, além do tamanho e tipo de edificações, envolvendo permacultura, materiais de baixo impacto, uso de energia solar, 
miniestações de tratamento de esgoto, cisternas, composteiras de resíduos sólidos, entre outros.

\section{Referências}

ALVARES, C.A. et al. Köppen's climate classification map for Brazil. Meteorologische Zeitschrift, vol. 22, n. 6, p. 711-728, 2014.

BEGALLI, M.; TRAVASSOS, L.; ZIONI, S. Atelier Ensaios Urbanos. Secretaria Municipal de Desenvolvimento Urbano (SMDU). 2014. Disponível em:

http://gestaourbana.prefeitura.sp.gov.br/atelier-ensaios-urbanos-2>. Acesso em: 3 dez. 2016.

BRASIL. Constituição da República Federativa do Brasil de 1988. Disponível em:

<http://www.planalto.gov.br/ccivil_03/constituicao/constituicao.htm>. Acesso em: 3 dez. 2016.

Decreto $n^{\circ} 1775$, de 8 de janeiro de 1996. Dispõe sobre o procedimento administrativo de demarcação das terras indígenas e dá outras providências. Disponível em:

<http://www.planalto.gov.br/ccivil_03/decreto/D1775.htm>. Acesso em: 11 dez. 2016.

Decreto $n^{\circ}$ 6.040, de 7 de fevereiro de 2007. Institui a Política Nacional de Desenvolvimento Sustentável dos Povos e Comunidades Tradicionais. Disponível em: <http://www.planalto.gov.br/ccivil_03/_ato2007-2010/2007/decreto/d6040.htm>. Acesso em: 3 dez. 2016.

. Decreto Federal $n^{\circ}$ 94. 222, de 14 de abril de 1987. Declara a ocupação indígena e homologa a demarcação administrativa da Área Indígena Rio Branco que menciona, no Estado de São Paulo. Disponível em: <http://www2.camara.leg.br/legin/fed/decret/19801987/decreto-9422314-abril-1987-444762-publicacaooriginal-1-pe.html>. Acesso em: $12 \mathrm{dez}$. 2016.

Lei $n^{\circ} 10.257$ de 10 de julho de 2001. Regulamenta os arts. 182 e 183 da Constituição Federal, estabelece diretrizes gerais da política urbana e dá outras providências. Disponível em: <http://www.planalto.gov.br/ccivil_03/leis/LEIS_2001/L10257.htm>. Acesso em: 10 dez. 2016.

Lei $n^{\circ}$ 11.428, 22 de dezembro de 2006. Dispõe sobre a utilização e proteção da vegetação nativa do Bioma Mata Atlântica, e dá outras providências. Disponível em <http://www.planalto.gov.br/ccivil_03/constituicao/constituicao.htm>. Acesso em 16 dez. 2016.

Lei $n^{\circ} 11.699$, de 13 de junho de 2008. Dispõe sobre as Colônias, Federações e Confederação Nacional dos Pescadores. Disponível em: <http://www.planalto.gov.br/ccivil_03/_ato2007-2010/2008/lei/l11699.htm>. Acesso em: 23 dez. 2016.

FUNAI. Website da Fundação Nacional do Índio. Funai delimita quatro terras indígenas do povo Mura, no Amazonas. Publicado em 15 de agosto de 2012. Disponível em: $<$ http://www.funai.gov.br/index.php/comunicacao/noticias/1751-funai-delimita-quatroterrasindigenas-do-povo-mura-no-amazonas>. Acesso em: 15 dez. 2016. 
FUNDAÇÃO SOS MATA ATLÂNTICA; INSTITUTO NACIONAL DE PESQUISAS ESPACIAIS. Atlas dos remanescentes florestais da Mata Atlântica e ecossistemas associados no período de 20052008. Relatório final: São Paulo, 2009. Disponível em:

<http://mapas.sosma.org.br/site_media/download/atlas\%20mata\%20atlanticarelatorio20052008.pdf >. Acesso em: $18 \mathrm{dez} .2016$.

IBGE. Instituto Brasileiro de Geografia e Estatística. Censo 2010. Disponível em: <http://www.censo2010.ibge.gov.br/>. Acesso em: 10 jan. 2016.

INSTITUTO FLORESTAL. Sistema de Informações Florestais do Estado de São Paulo. Disponível em: <http://www.iflorestal.sp.gov.br/sifesp/regional.html>. Acesso em: 3 dez. 2016.

KLEIN, N. This Changes Everything: Capitalism vs The Climate. Simon \& Schuster, 2014.

LIMA, A. Política Florestal. In: Campanili, M. (Ed). Almanaque Brasil SocioAmbiental. Instituto SocioAmbiental: São Paulo, p. 274-275, 2007.

MANTOVANI, W. Entrevista: Biodiversidade Riacho Grande. Mensagem recebida de waldir.mantovani@ufabc.edu.brem 22 jun. 2015.

MARQUES, L. Capitalismo e Colapso Ambiental. Campinas: Unicamp, 2015.

MYERS, N.; MITTERMEIER, R. A.; MITTERMEIER, C. G.; FONSECA, G. A. B.; KENT, J. Biodiversity hotspots for conservation priorities. Nature, 403: 853-858, 2000.

OLMOS, F.; STEINER, C.; GALETTI, M. O impacto dos Guarani sobre Unidades de Conservação em São Paulo." In: Fanny, R. (Org.). Terras indígenas e unidades de conservação da natureza: 0 desafio das sobreposições. João Pessoa: Socioambiental, 2004. Disponível em: <http://www.ambiente.sp.gov.br/wp-content/uploads/cea/Texto_Galetti.pdf>. Acesso em: 15 dez. 2016.

OSTROM, E. A general framework for analyzing Sustainability of social-ecological systems. Science, n. 325, p. 419-422, 2009.

PMSBC. Prefeitura do Município de São Bernardo do Campo. Lei $n^{\circ} 6184$ de 21 de dezembro de 2011. Dispõe sobre a criação do Plano Diretor do Município de São Bernardo do Campo, e dá outras providências. Disponível em:

<http://www.saobernardo.sp.gov.br/documents/10181/23112/L.M.6184-11_Plano_Diretor\%5Bcompilada_at\%C3\%A9_15-12-14\%5D.pdf/239b21e8-c3ef-4cee-8d8b-a384c7e8dcc6>. Acesso em: 14 nov. 2016.

Decreto $n^{\circ} 18.684$, de 13 de novembro de 2013. Cria o Parque Natural Municipal Estoril Virgílio Simionato, e dá outras previdências. Website Leis Municipais. Disponível em: <https://www.leismunicipais.com.br/a/sp/s/sao-bernardo-docampo/decreto/2013/1869/18684/decreto-n-18684-2013-cria-o-parque-natural-municipalestoril virgilio-simionato-e-da-outras-providencias?q=parque\%20estoril $>$. Acesso em: 3 dez. 2016. 
Perfil Socioeconômico por bairros. 2015. Disponível em:

<http://www.saobernardo.sp.gov.br/perfil-socioeconomico-por-bairros $>$. Acesso em: 8 dez. 2016.

PORTO, L. C. S.; ETHUR, E. M. Elementos traço na água e em vísceras de peixes da Bacia Hidrográfica Butuí-Icamaquã, Rio Grande do Sul, Brasil. Ciência Rural, n. 39, v. 9: p. 2512-2518, 2009. Disponível em: <http://www.scielo.br/scielo.php?script=sci_arttext\&pid=S010384782009000900020\&lng=en\&tlng=pt>. Acesso em: 17 nov. 2016.

ROCHA, A. A.; PEREIRA, D. N.; PÁDUA, H. B. Produtos de pesca e contaminantes químicos na água da Represa Billings, São Paulo (Brasil). Revista de Saúde Pública, v. 19, n. 5, p. 401-410, 1985. Disponível em:

<http://www.scielosp.org/scielo.php?script=sci_arttext\&pid=S003489101985000500003\&lng=e n\&tlng=pt.10.1590/S0034-89101985000500003>. Acesso em: 1 dez. 2016.

SÃO PAULO. Decreto $n^{\circ} 10.251$ de 30 de agosto de 1977. Cria o Parque Estadual da Serra do Mar e dá outras providências. Disponível em:

<http://www.al.sp.gov.br/repositorio/legislacao/decreto/1977/decreto-10251-

30.08.1977.html>. Acesso em: 1 dez. 2016.

Resolução $n^{\circ} 34$ de 19 de setembro de 2006 do Conselho Estadual do Meio Ambiente. Aprovou o Plano de Manejo do Parque Estadual da Serra do Mar elaborado pelo Instituto Florestal. Disponível em:

<http://www.ambiente.sp.gov.br/consema/files/deliberacoes/2006/Del34.zip>. Acesso em: 10 jan. 2016.

Parque Estadual Serra do Mar: Plano de Manejo. Secretaria do Meio Ambiente: Instituto Florestal. 2008. Disponível em: <http://fflorestal.sp.gov.br/files/2012/01/2-VolumePrincipal-Completo_com-mapas-parte1-01a52.pdf>. Acesso em: 15 nov. 2016.

Lei $n^{\circ} 13.579$, de 13 de julho de 2009. Define a Área de Proteção e Recuperação dos Mananciais da Bacia Hidrográfica do Reservatório Billings - APRM-B. Disponível em: <http://www.al.sp.gov.br/repositorio/legislacao/lei/2009/lei-13579-13.07.2009.html>. Acesso em: 20 dez. 2016.

Ecoturismo: Parque Estadual Serra do Mar Reabre para Visitação Pública. Website do Governo do Estado de São Paulo. Publicado em 6 de julho de 2015. Disponível em: <http://www.saopaulo.sp.gov.br/spnoticias/lenoticia2.php?id=241461>. Acesso em: 3 dez. 2016.

SGA. Secretaria de Gestão Ambiental de São Bernardo do Campo. Zoneamento do Estoril. Mensagem recebida de melina.oliveira@saobernardo.sp.gov.br em 13 nov. 2016.

UNESCO. United Nations Educational, Scientific, Social and Cultural Organization. 2015. Website da UNESCO. World Heritage List. Atlantic Forest South-East Reserves. Disponível em: <http://whc.unesco.org/en/list/893>. Acesso em: 7 dez. 2016.

VELASQUEZ, C. Áreas Protegidas. In: RICARDO, B.; CAMPANILLI, M. Almanaque Brasil Socioambiental. Instituto Socioambiental, São Paulo. p. 261-270, 2007. 